\title{
Ejecting chick cheats: a changing paradigm?
}

\author{
Tomáš Grim
}

\begin{abstract}
Evolutionary arms-races between avian brood parasites and their hosts have typically resulted in some spectacular adaptations, namely remarkable host ability to recognize and reject alien eggs and, in turn, sophisticated parasite egg mimicry. In a striking contrast to hosts sometimes rejecting even highly mimetic eggs, the same species typically fail to discriminate against highly dissimilar parasite chicks. Understanding of this enigma is still hampered by the rarity of empirical tests - and consequently evidence - for chick discrimination. Recent work on Australian host-parasite systems (Gerygone hosts vs. Chalcites parasites), increased not only the diversity of hosts showing chick discrimination, but also discovered an entirely novel host behavioural adaptation. The hosts do not desert parasite chicks (as in all previously reported empirical work) but physically remove living parasites from their nests. Here, I briefly discuss these exciting findings and put them in the context of recent empirical and theoretical work on parasite chick discrimination. Finally, I review factors responsible for a relatively slow progress in this research area and suggest most promising avenues for future research.
\end{abstract}

\section{Introduction}

Science advances by a triad of major types of contributions: most frequently by collecting data to test hypotheses that were already formulated or tested by others (most papers in any scientific journal), less often by suggesting novel hypotheses (e.g. [1]) and most rarely by discovering completely new and unexpected natural phenomena (e.g. [2]). Recent work by Sato et al. [3] and Tokue and Ueda [4] belong to this last category of scientific endeavour. These two studies showed for the first time that hosts of parasitic birds (genus Gerygone) may defend against alien (little bronze-cuckoo Chalcites minutillus) chicks by physically removing the living parasite from the nest, so saving the lives of their own nestlings. This qualitatively novel host behaviour contrasts with host deserting [5], feeding less [6] or pecking [7] parasite chicks which were the only anti-chick defences documented so far. Coupled with other recent studies of parasite chick discrimination $[7,8]$, these findings have important implications for our understanding of host-parasite relationships specifically and parent-offspring interactions in general.

Correspondence: tomas.grim@upol.cz

Department of Zoology and Laboratory of Ornithology, Palacký University, třr. Svobody 26, 77146 Olomouc, Czech Republic

\section{A novel host anti-parasite adaptation}

Interactions between brood parasites and their hosts are one of the most intensely studied natural models of coevolution, recognition and learning [9-11]. Until recently, the majority view of host defences to mitigate costs of parasitism was that most host species reject at least some proportion of alien eggs but that hosts typically accept alien chicks (reviewed in [12-14]). Virtually any paper or textbook on brood parasitism is a testimony of this (for an exception see [15]). Some studies even claimed 'hosts do not reject nestlings' [16] despite rare but existing evidence to the contrary (see older references in Table one in [12]). This view prevailed for decades despite rarity of any thorough studies on host responses to alien nestlings [13]. Further, theoretical arguments seemed to explain an apparent absence of chick discrimination. An elegant and influential model by A. Lotem [17] showed that imprinting on the first clutch/egg is adaptive in hosts of evicting parasites whereas imprinting on the first brood/chick is maladaptive. However, the model was based on a critical assumption of learned recognition with naïve breeders being unable to reject the parasite by definition (thus, the model does not hold for non-learned innate recognition, see p. 744 in [17]). That assumption does not hold empirically for many hosts because already first-year naïve breeders often reject parasitism and no effects of female age on her ability to recognize parasite eggs were 
typically found [e.g. [18-20], Grim, Samaš, Cassey and Hauber in prep.] (this, of course, does not exclude an age-related fine-tuning of innate or learned discrimination abilities in other host species [21]). Also, Lotem's model [17] is unlikely to apply in hosts that show $\sim 100$ rejection of alien eggs, i.e., there is no inter-individual, and by implication intra-individual variation in host behaviour [22,23]. Limited data for parasite chick discrimination in relation to host individual experience $[5,6]$ also suggest that the misimprinting model does not apply to chick discrimination in the host-parasite systems studied so far (but see [7] for a case of conspecific parasites). As the known biological reality of inter-specific parasites does not generally fit assumptions of the Lotem's model [17], the misimprinting argument does not constrain chick discrimination [5,6,12,24-26].

Brood parasitism literature was always heavily biased in favour of egg discrimination [13]. However, absence of evidence is not evidence of absence and, strikingly, all recent papers that looked for parasite chick discrimination by hosts have found some evidence for host differential responses to alien nestlings ([3-5,7,27,28]; see also p. 750 in [29] and [30]; earlier studies reviewed in $[12,31])$. Although there are many studies based on nests with parasite chicks, they typically did not follow parasite chicks up till fledging. Such studies are inconclusive because discrimination can occur shortly before $[27,31]$ or even after fledging [32]. There are few careful studies showing that chick rejection does not occur [9]. So, why are the new studies $[3,4]$ so exciting?

The most striking aspect of the newly described chick discrimination systems $[3,4]$ is that chicks were not simply abandoned (as in the previous studies documenting chick discrimination under natural conditions [12]). Instead, hosts grasped the parasite nestlings with their beaks and ejected them from their nests. Although eviction of dead chicks is known as an expression of nestcleaning behaviour in many birds (discussed in [12]), such behaviour was never previously observed in the context of host-parasite interactions.

Tokue and Ueda [4] work is further exciting for another reason. Previously reported chick discrimination host responses were highly costly to hosts in terms of (a) prolonged care for the parasite chick before its desertion [33], (b) high rates of rejection errors [3], or (c) a complete loss of host own progeny ([5]; but see [7] for a case study of conspecific brood parasites). In contrast, Tokue and Ueda [4] showed that chick discrimination may take place (a) almost immediately after the parasite hatches, and (b) without rejection errors (though in small sample sizes), thus (c) rejecting host individuals saved their whole current parental investment before the parasite chick had a chance to destroy it.
Supplementary video materials to both Sato et al. [3] and Tokue and Ueda [4] clearly demonstrate that such a physical task is feasible even for small hosts like Gerygone warblers. As clear terminology is essential to science, I suggest the removal of alien chicks is referred to not as 'eviction' (as in [3]) but as 'ejection'. By definition, eviction is performed by a cuckoo chick when pushing host eggs and/or nestlings from a host nest (see $[9,34,35]$ and references therein). In contrast, ejection is performed by a host parent when removing parasite eggs (or nestlings) from its nest [9].

Admittedly, sample sizes were limited in both new chick ejection studies. Still, in a Popperian vein, even a single observation of hosts rejecting an alien chick falsifies the hypothesis that hosts always accept them. Of course, as in the egg discrimination studies, we need to consider a possibility of chick recognition errors (as documented by Sato et al. [3]). However, such errors themselves suggest that hosts respond to chick own-vs.-parasite identity. Also, we need more detailed data showing that ejected nestlings did not suffer from a disease - birds are known to remove sick and/or dead chicks from their nests (see references in [12]).

Another aspect of the two Gerygone-Chalcites studies that should be highlighted is methodological. Both papers provided readers with direct video-recording evidence of chick discrimination (see the supplementary on-line video files for both studies). No paper on egg discrimination has provided readers with such direct evidence perhaps because some journals are reluctant to publish electronic supplementary files. Still, various journals did publish supplementary video files for brood parasitism studies but solely for studies of parasitic chicks $[2-4,7,36]$. Perhaps journal editors and reviewers do not encourage it because egg discrimination is a well-known phenomenon, unlike chick discrimination. In the future, such video-recording evidence might be published as a useful supplementary material in egg discrimination studies too.

Egg discrimination studies often lack controls (see, e.g., the three published studies with the highest sample size: $[28,37,38])$. Specifically, egg discrimination studies did not always include control unmanipulated nests (to quantify background nest desertion rates that are not a response to parasitism) and/or observed nests directly (to exclude a risk that a parasite egg disappeared not by host ejection but by being removed by predators, brood parasites, or conspecifics). Both Sato et al. [3] and Tokue and Ueda [4] employed control nests for comparisons and monitored nests by continuous video-recording. This might inspire future egg discrimination studies to rest on more robust methodologies than before. 
The present arguments are not meant to devalue the egg studies in any way - only by pinpointing imperfections of our past research we can improve it in the future. This holds for studies of both eggs and chicks. Further, research at the chick stage should not constrain but complement research at the egg stage. Overall, I explicitly stress the importance of balanced empirical and theoretical research at all developmental stages, i.e., eggs, chicks and adults [28].

\section{New findings fit theory}

From a theoretical point of view it is remarkable that both systems fit predictions from theory. Both the 'rarer enemy effect' [12], an extension of rare enemy effect, and the 'strategy-blocking' models $[25,26]$ predict that chick discrimination should evolve mostly in hosts that do not successfully reject natural cuckoo parasitism (i.e., hosts are either acceptors of any, even highly dissimilar foreign eggs, or their existing rejection abilities are compromised by evolved cuckoo egg mimicry). This is essentially because of the asymmetry of cost/benefit ratios of egg vs. chick discrimination (chick discrimination requires stronger selection pressure to evolve than egg discrimination [12]) and an inevitable fact that the parasite is always present in a host nest earlier as an egg and only later in the form of a nestling. Obviously, a host correctly rejecting parasite eggs ('rare enemies') will have no chance to face parasite chicks (which, as a consequence of host own behaviour, become even 'rarer enemies'). Paradoxically, egg-rejecting hosts themselves eliminate selection pressure that would enable them to evolve an ability to discriminate parasite chicks [12]. Thus, successful previous lines of defence (including nest defence [39]) decrease positive selection pressure on later lines of defence. Indeed, gerygones are currently acceptors of natural cuckoo eggs ([3], see also Table one in [12]) and, interestingly, recent work [40] suggests that this might not be because of mimicry but because dark cuckoo eggs are cryptic in dark host domed nests. Still, this has the same consequences for evolution of host defences - egg crypsis forces hosts to accept parasitism at the egg stage similar to egg mimicry, phylogenetic constraints and other mechanisms responsible for high similarity in host vs. parasite phenotypes [41].

Given that gerygones are able to eject non-mimetic experimental eggs ( $\mathrm{R}$. Noske pers. comm.) it is possible that cryptic cuckoo eggs evolved as an evolutionary response to host discrimination simply because dark cryptic eggs would escape visual host discrimination. This novel hypothesis provides an alternative explanation for the evolution of cryptic eggs not considered by Langmore et al. [40]. Evolution of mimetic eggs (similar to host eggs) or cryptic eggs (similar to dark nest interiors) represent two alternative pathways with effectively the same consequences - both cryptic or mimetic egg appearances force hosts to accept parasitism and reduce selection pressure on the evolution of chick discrimination $[12,40]$.

Older empirical data fit the rarer enemy effect well (Table one in [12]) and the strategy-blocking models $[25,26]$ and novel observations by Sato et al. [3] and Tokue and Ueda [4] support the same views (see also [30]). Additionally, low clutch sizes and high risks of multiple parasitism by cuckoos may contribute to chick ejection being a more adaptive strategy than egg ejection in these hosts (the 'egg dilution effect' hypothesis [42]).

Chick ejections from the new studies [3,4] are compatible with both innate $[12,26]$ and learned $[17,43]$ discrimination. Although it is unlikely, due to the short exposure of hosts to their own chicks, the latter option cannot at present be safely evaluated because the ejected cuckoo chicks hatched shortly after the host chicks (see also [7] and a discussion of 'sibling imprinting' in [24]). Only one study [44] followed individuals of known breeding histories to test the effects of experience on desertion of a single parasite vs. a single own chick under natural unmanipulated conditions in the superb fairy-wrens Malurus cyaneus. Nothing is known about parental age effects on chick discrimination (and, by implication, about innate and learned bases of such discrimination) in both chick-ejecting gerygones and any other study systems with presumed or documented defence against nestling parasites (but see a laboratory study [6]). Long-term experimental studies with individually marked naïve first-time breeders with subsequently manipulated breeding histories (cf. natural unmanipulated observations in [44]) are needed to see whether and how chick discrimination ability changes during an individual's lifetime.

It remains to be seen whether the prevalence of parasite chick ejection extends to other gerygone congeners (that are often victimized by Chalcites cuckoos). If so, the genus Gerygone may become an excellent model for the study of parasite-host coevolution at the nestling stage.

\section{Constraints on detecting and studying chick discrimination}

What is the general lesson from recent studies on chick discrimination? The traditional conception of host inability to discriminate against divergent nestlings was misleading. Why?

(a) Due to fundamental differences in avian and human vision it makes little sense to look at host vs. parasite phenotypes and judge their similarity $[41,45]$. All previous studies that claimed dis/similarity of host vs. parasite nestlings were based on subjective human vision-based assessment. Only very recently, the 
assumption of chick differences was tested by objective analyses of what host parents really perceived [8].

(b) Hosts may pay attention only to a specific trait (e. g., gape colour reflectance in UV) and ignore other, perhaps less informative (but for humans more conspicuous!) traits (see also $[8,46])$. Such mechanisms were already documented in the context of egg discrimination: some hosts pay attention to UV and blue colours but ignore other regions of egg reflectance spectra [45] and discriminate alien eggs based on blunt - but not sharp - egg pole appearance $[47,48]$.

(c) In contrast to egg discrimination, which is primarily or solely a visual task (which fits human sensory biases), the discrimination of chick impostors might be based on single or combined visual, acoustical or even olfactory cues (that are harder to detect in the visiondominated human sensory world [5,12]). Additionally, I suggest a novel potential cue for chick discrimination: chick behaviour, e.g., posturing or wing-shaking, typically differs between host and parasite chicks [36], and, thus, hosts might base their discrimination on such behavioural traits. Also the eviction behaviour is performed solely by cuckoo nestlings and, consequently, might be used by hosts to identify the parasite [30]. This hypothesis could be tested in host-parasite systems where the behaviour of nestling parasites deviates from that of host nestlings (examples reviewed in [36]). Further, discrimination cues were typically tested in isolation in previous studies (e.g., visual cues only: [46]; acoustical cues only: [49]). I suggest, that a particular cue may not work per se, or additively with another cue, but could trigger discrimination only in interaction with other cues (for an example of testing a similar 'interactive' hypothesis see [28]).

(d) Discrimination need not rely on recognition cues host-parasite chick similarity may be irrelevant for host decisions to accept or reject chicks. Recognition-free discrimination mechanisms rest on predictable differences in non-phenotypic cues associated with the presence of a parasite chick in the host nest. Such external cues include brood size [3], amounts of care in terms of feeding rates [33], or the length of parental care [27]. Except for one work [27], external cues like provisioning costs or temporal costs of care were not experimentally manipulated in any study of chick discrimination.

(e) Chick discrimination may result not only in an outright rejection of the parasite by ejection $[3,4]$, pecking [50], desertion [27] or starvation [51] but may also be manifested in feeding parasites with a lower quality [52] and/or quantity of prey [53]. Consequently, parasite chicks may only decrease in growth instead of dying [46]. This makes potentially continuous chick discrimination harder to detect than a dichotomous host decision to remove an alien egg or to let it stay in the nest. (f) Some subtler tactics of chick discrimination happen at temporal scales of days [5] to weeks [33]. Thus, they are much harder to detect than a simple act of egg ejection that occurs at temporal scales of days, hours or even seconds [9].

(g) Chick discrimination may be poorly developed before fledging [31]. Very few studies followed the fates of parasitized nests up to fledging (reviewed in [12,31]; see also [33-35]. Moreover, discrimination may start after fledging $[12,32]$ and we lack detailed info on postfledging care in most host-parasite systems [9].

(h) That hosts accept parasite chicks under natural conditions does not mean that hosts lack chick discrimination abilities - those might be countered by evolved chick mimicry (just like egg rejecters are sometimes forced to accept alien eggs that are highly mimetic $[9,15,22])$. Therefore, without experimental manipulation of chick traits [46] or testing host responses to chicks of different species [6] it is not possible to say anything conclusive on the existence or absence of chick discrimination in any host.

On the other hand, not all cases of parasite chicks not thriving in host nests are evidence for specific host antichick defences [14,53]. Also, similarities between parasite and host chicks is not evidence of mimicry, or, by implication, of chick discrimination. This is because such similarities may be non-mimetic - they may arise due to multiple reasons unrelated to brood parasitism [41]. Thus, studying mechanisms of chick discrimination provides theoretically, logistically and interpretatively more challenging tasks than the research on egg discrimination does. These eight factors, coupled with the previous rarity of empirical work, may explain the traditional myth of the absence/rarity of chick discrimination.

\section{Conclusions}

Recent years have seen an increasing interest in host responses to parasite chicks (14) and empirical data for chick discrimination has begun to accumulate. This shifting paradigm has already been reflected in some textbooks $[10,11]$. Where to next?

(a) Various recent studies (see above) showed that just because chick discrimination is not easy to document, does not mean that it is non-existent or unimportant. An emerging picture is that rejection of chick cheats may not be a rare phenomenon. Clearly, more thorough documentation of host abilities to reject alien chicks across different species is needed (see also p. 750 in [29]) as a starting point for future studies of causes and consequences of host chick discrimination. Candidate study systems are plenty $[12,28,30,31]$.

(b) Several studies $[7,27,49]$ confirm experimental tractability of diverse chick discrimination systems. Still, 
except for a single well studied system $[5,8,40,44,49]$ we know next to nothing about proximate chick phenotype cues that trigger parental discrimination, repeatability and heritability of chick discrimination abilities, or how an ability to discriminate is moulded by experience. Generally, we have no information on what the specific mechanisms of discrimination at the cognitive, neural and physiological levels from any host are. This holds also for egg studies. Further, non-representative sampling across host taxa and low research effort in this study area prevent analyses of phylogenetic patterns of chick discrimination. Better knowledge of the phylogenetic distribution of chick discrimination will enable us to address additional exciting questions, e.g., which lifehistory host traits facilitate or constrain evolution of host defences against foreign chicks [24] and whether discrimination of alien chicks by particular hosts is a specific co-evolutionary adaptation or 'collateral damage' resulting from general host life-history traits unrelated to parasitism per se $[28,54]$.

(c) The successful incorporation of objective measurements of parasite/host phenotypic dissimilarity coupled with realistic modelling of how hosts perceive such dissimilarity [23,45,55-57] was a major advance for brood parasitism studies at the egg stage. However, we still lack studies that would parallel such advances at the nestling stage (but see $[8,58]$ ).

(d) An understanding of chick discrimination will be further enhanced if theoretical models $[12,17,25,26,43]$ and empirical data will mutually inform each other.

In the past, the study of brood parasitism at the egg stage was mostly empirical whereas studies at the nestling stage mostly relied on theoretical work $[9,17]$. Recently, the parasite nestling field went through the discovery stage of scientific work with various cases of chick discrimination being found across the globe. It is exciting to see that future experimental work on broodparasite host arms-races, as a textbook example of coevolution, is no longer hindered by the lack of suitable model study systems.

\footnotetext{
Acknowledgements

I am grateful to Diane Colombelli-Negrel, Paul Donald, Becky Kilner, Bruce Lyon, Daizaburo Shizuka, Manuel Soler, Bard Stokke, Kihoko Tokue for their helpful comments on earlier versions of the manuscript. Comments from three anonymous reviewers greatly improved this work. Dana Campbell corrected the language. My research is supported by Human Frontier Science Program (RGY69/07) and MSM6198959212.
}

\section{Competing interests}

The author declares that he has no competing interests.

Received: 4 May 2011 Accepted: 13 June 2011 Published: 13 June 2011

\section{References}

1. Zahavi A: Mate selection: a selection for a handicap. J Theor Biol 1975, 53:205-214.
2. Tanaka KD, Ueda K: Horsfield's hawk-cuckoo nestlings simulate multiple gapes for begging. Science 2005, 308:653-653.

3. Sato NJ, Tokue K, Noske RA, Mikami OK, Ueda K: Evicting cuckoo nestlings from the nest: a new anti-parasitism behaviour. Biol Lett 2010, 6:67-69.

4. Tokue K, Ueda K: Mangrove Gerygones Gerygone laevigaster eject Little Bronze-cuckoo Chalcites minutillus hatchlings from parasitized nests. Ibis 2010, 152:835-839.

5. Langmore NE, Hunt S, Kilner RM: Escalation of a coevolutionary arms race through host rejection of brood parasitic young. Nature 2003, 422:157-160

6. Payne RB, Woods $J$, Payne LL: Parental care in estrildid finches: experimental tests of a model of Vidua brood parasitism. Anim Behav 2001, 62:473-483.

7. Shizuka D, Lyon BE: Coots use hatch order to learn to recognize and reject conspecific brood parasitic chicks. Nature 2010, 463:223-226.

8. Langmore NE, Stevens M, Maurer G, Heinsohn R, Hall ML, Peters A, Kilner RM: Visual mimicry of host nestlings by cuckoos. Proc R Soc Lond $B$

9. Davies NB: Cuckoos, cowbirds and other cheats. London: T \& A D Poyser; 2000.

10. Danchin É, Giraldeau LC, Cézilly F: Behavioural Ecology. Oxford: OUP; 2008.

11. Alcock J: Animal Behavior. Sunderland: Sinauer Associates; 92009.

12. Grim T: The evolution of nestling discrimination by hosts of parasitic birds: why is rejection so rare? Evol Ecol Res 2006, 8:785-802.

13. Grim T: Equal rights for chick brood parasites. Ann Zool Fennici 2007, 44:1-7.

14. Soler M: Co-evolutionary arms race between brood parasites and their hosts at the nestling stage. J Avian Biol 2009, 40:237-240.

15. Stokke BG, Moksnes A, Røskaft E: The enigma of imperfect adaptations in hosts of avian brood parasites. Ornithol Sci 2005, 4:17-29.

16. Winfree R: Cuckoos, cowbirds and the persistence of brood parasitism. Trends Ecol Evol 1999, 14:338-342.

17. Lotem A: Learning to recognize nestlings is maladaptive for cuckoo Cuculus canorus hosts. Nature 1993, 362:743-745.

18. Marchetti K: Egg rejection in a passerine bird: size does matter. Anim Behav 2000, 59:877-883.

19. Amundsen T, Brobakken PT, Moksnes A, Røskaft E: Rejection of common cuckoo Cuculus canorus eggs in relation to female age in the bluethroat Luscinia svecica. J Avian Biol 2002, 33:366-370.

20. Stokke BG, Rudolfsen G, Moksnes A, Røskaft E: Rejection of conspecific eggs in chaffinches: the effect of age and clutch characteristics. Ethology 2004, 110:459-470.

21. Lotem A, Nakamura H, Zahavi A: Rejection of cuckoo eggs in relation to host age: a possible evolutionary equilibrium. Behav Ecol 1992, 3:128-132.

22. Honza M, Procházka P. Stokke BG, Moksnes A, Røskaft E, Čapek M, Mrlík V: Are blackcaps current winners in the evolutionary struggle against the common cuckoo? J Ethol 2004, 22:175-180.

23. Vikan JR, Stokke BG, Fossøy F, Jackson C, Huhta E, Rutila J, Moksnes A, Røskaft E: Fixed rejection responses to single and multiple experimental parasitism in two Fringilla hosts of the common cuckoo. Ethology 2009, 115:840-850.

24. Krüger $\mathrm{O}$ : Cuckoos, cowbirds and hosts: adaptations, trade-offs and constraints. Phil Trans R Soc B 2007, 362:1873-1886.

25. Planqué $R$, Britton NF, Franks NR, Peletier MA: The adaptiveness of defence strategies against cuckoo parasitism. Bull Math Biol 2002, 64:1045-1068.

26. Britton NF, Planqué R, Franks NR: Evolution of defence portfolios in exploiter-victim systems. Bull Math Biol 2007, 69:957-988.

27. Grim T: Experimental evidence for chick discrimination without recognition in a brood parasite host. Proc R Soc Lond B 2007, 274:373-381.

28. Grim T, Samaš P, Moskát C, Kleven O, Honza M, Moksnes A, Røskaft E, Stokke BG: Constraints on host choice: why do parasitic birds rarely exploit some common potential hosts? J Anim Ecol 2011, 80:508-518

29. Honza M, Procházka P, Šicha V, Požgayová M: Nest defence in a cuckoo host: great reed warblers risk themselves equally for their own and parasitic chicks. Behaviour 2010, 147:741-756.

30. Hegemann A, Voesten R: Can skylarks Alauda arvensis discriminate a parasite nestling? Possible case of nestling cuckoo Cuculus canorus ejection by its host parents. Ardea 2011, 99:117-120.

31. Redondo T: Exploitation of host mechanisms for parental care by avian brood parasites. Etología 1993, 3:235-297. 
32. Fraga RM: Interactions of the parasitic screaming and shiny cowbirds (Molothrus rufoaxillaris and $M$. bonariensis) with a shared host, the baywinged cowbird (M. badius). In Parasitic Birds and Their Hosts. Edited by: Rothstein SI, Robinson SK. New York: Oxford University Press; 1998:173-193.

33. Grim T, Kleven O, Mikulica O: Nestling discrimination without recognition: a possible defence mechanism for hosts towards cuckoo parasitism? Proc R Soc Lond B 2003, 270:S73-S75.

34. Anderson MG, Moskát C, Bán M, Grim T, Cassey P, Hauber ME: Egg eviction imposes a recoverable cost of virulence in chicks of a brood parasite. PLOS ONE 2009, 4:e7725.

35. Grim T, Rutila J, Cassey P, Hauber ME: The cost of virulence: an experimental study of egg eviction by brood parasitic chicks. Behav Ecol 2009, 20:1138-1146.

36. Grim T: Wing-shaking and wing-patch as nestling begging strategies their importance and evolutionary origins. J Ethol 2008, 26:9-15.

37. Davies NB, Brooke M, de L: An experimental study of co-evolution between the cuckoo, Cuculus canorus, and its hosts. I. Host egg discrimination. J Anim Ecol 1989, 58:207-224.

38. Moksnes A, Røskaft E, Braa AT, Korsnes L, Lampe HM, Pedersen HC: Behavioural responses of potential hosts towards artificial cuckoo eggs and dummies. Behaviour 1991, 116:64-89.

39. Welbergen JA, Davies NB: Strategic variation in mobbing as a front line of defense against brood parasitism. Cur Biol 2009, 19:235-240.

40. Langmore NE, Stevens M, Maurer G, Kilner RM: Are dark cuckoo eggs cryptic in host nests? Anim Behav 2009, 78:461-468

41. Grim T: Mimicry vs. similarity: which resemblances between brood parasites and their hosts are mimetic and which are not? Biol J Linn Soc 2005, 84:69-78.

42. Sato NJ, Mikami OK, Ueda K: Egg dilution effect hypothesis: a condition under which parasitic nestling ejection behaviour will evolve. Ornithol Sci 2010, 9:115-121.

43. Lawes MJ, Marthews TR: When will rejection of parasite nestlings by hosts of nonevicting avian brood parasites be favored? A misimprintingequilibrium model. Behav Ecol 2003, 14:757-770.

44. Langmore NE, Cockburn A, Russell AF, Kilner RM: Flexible cuckoo chickrejection rules in the superb fairy-wren. Behav Ecol 2009, 61:497-503.

45. Cassey P, Honza M, Grim T, Hauber ME: The modelling of avian visual perception predicts behavioural rejection responses to foreign egg colours. Biol Lett 2008, 4:515-517.

46. Schuetz JG: Reduced growth but not survival of chicks with altered gape patterns: implications for the evolution of nestling similarity in a parasitic finch. Anim Behav 2005, 70:839-848.

47. Polačiková L, Grim T: Blunt egg pole holds cues for alien egg discrimination: experimental evidence. J Avian Biol 2010, 41:111-116.

48. Polačiková L, Stokke BG, Procházka P, Honza M, Moksnes A, Røskaft E: The role of blunt egg pole characteristics for recognition of eggs in the song thrush (Turdus philomelos). Behaviour 2010, 147:465-478.

49. Langmore NE, Maurer G, Adcock GJ, Kilner RM: Socially acquired hostspecific mimicry and the evolution of host races in Horsfield's bronzecuckoo Chalcites basalis. Evolution 2008, 62:1689-1699.

50. Soler M, Soler JJ, Martinez JG, Møller AP: Chick recognition and acceptance: a weakness in magpies exploited by the parasitic great spotted cuckoo. Behav Ecol Sociobiol 1995, 37:243-248.

51. Lichtenstein G: Low success of shiny cowbird chicks parasitizing rufousbellied thrushes: chick-chick competition or parental discrimination? Anim Behav 2001, 61:401-413.

52. Soler M: Do hosts of interspecific brood parasites feed parasitic chicks with lower-quality prey? Anim Behav 2008, 76:1761-1763.

53. Schuetz JG: Low survival of parasite chicks may result from their imperfect adaptation to hosts rather than expression of defenses against parasitism. Evolution 2005, 59:2017-2024.

54. Davies NB: Cuckoo adaptations: trickery and tuning. J Zool 2011, 284:1-14.

55. Antonov A, Stokke BG, Vikan JR, Fossøy F, Ranke PS, Røskaft E, Moksnes A, Møller AP, Shykoff JA: Egg phenotype differentiation in sympatric cuckoo Cuculus canorus gentes. J Evol Biol 2010, 23:1170-1182.

56. Spottiswoode CN, Stevens M: Visual modeling shows that avian host parents use multiple visual cues in rejecting parasitic eggs. $P$ Natl Acad Sci USA 2010, 107:8672-8676.

57. Vikan JR, Stokke BG, Rutila J, Huhta E, Moksnes A, Røskaft E: Evolution of defences against cuckoo (Cuculus canorus) parasitism in bramblings
(Fringilla montifringilla): a comparison of four populations in Fennoscandia. Evol Ecol 2010, 24:1141-1157.

58. Anderson MG, Ross HA, Brunton DH, Hauber ME: Begging call matching between a specialist brood parasite and its host: a comparative approach to detect coevolution. Biol J Linn Soc 2009, 98:208-216.

doi:10.1186/1742-9994-8-14

Cite this article as: Grim: Ejecting chick cheats: a changing paradigm? Frontiers in Zoology 2011 8:14.

\section{Submit your next manuscript to BioMed Central and take full advantage of:}

- Convenient online submission

- Thorough peer review

- No space constraints or color figure charges

- Immediate publication on acceptance

- Inclusion in PubMed, CAS, Scopus and Google Scholar

- Research which is freely available for redistribution

Submit your manuscript at www.biomedcentral.com/submit
Biomed Central 